\title{
PERSPECTIVAS Y CAUCES PROCEDIMENTALES DE LA REMUNICIPALIZACIÓN DE SERVICIOS
}

\author{
JOSÉ ESTEVE PARDO' \\ Universidad de Barcelona \\ jestevep@ub.edu
}

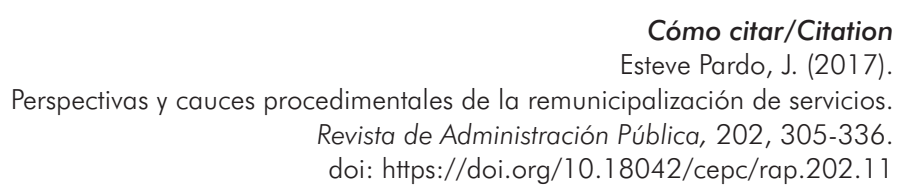

Resumen

El movimiento remunicipalizador — que fundamentalmente pretende la recuperación de la gestión directa sobre servicios locales - ha obtenido algunos logros resonantes en algunas de las grandes ciudades europeas. Pero si se analizan los resultados en su conjunto se comprueba que el impacto de la remunicipalizción en países del sur de Europa, España entre ellos, ha sido muy bajo, afectando solo a una docena de pequeńos municipios. El diferente entorno económico conformado por la reciente crisis económica explica la más sólida cobertura financiera de los municipios del norte y centro de Europa. Le reciente reforma del régimen local español, que se produce en esa situación de crisis, no favorece los objetivos de la remunicipalización al dar entrada a las autoridades de defensa de la competencia y optar prioritariamente por la gestión indirecta de los servicios locales.

\section{Palabras clave}

Gestión servicios locales; procedimiento administrativo; autoridades de la competencia; derecho comparado.

1 Catedrático de Derecho Administrativo. 


\section{Abstract}

The remunicipalization's movement has achieved important success in some European great cities. However, if we analyse the overall results we will realise the impact in the south of Europe has been very poor. Only a dozen of municipalities have been affected. This is due to the economical difference between the north and the south of Europe. The recent legal reforms of the local governments in Spain, approved in the heart of the crisis, don't support the direct management of the local services.

\section{Keywords}

Comparative law; administrative procedure; local governments; local public services; public services management. 


\section{SUMARIO}

I. EL MOVIMIENTO REMUNICIPALIZADOR. SUS PLANTEAMIENTOS Y SUS DIVERSOS ENTORNOS. II. LAS INEXCUSABLES EXIGENCIAS PROCEDIMENTALES EN LAS INICIATIVAS REMUNICIPALIZADORAS. III. POSICIONES QUE PUEDE OSTENTAR EL MUNICIPIO SOBRE SUS SERVICIOS: COMPETENCIA Y TITULARIDAD. IV. LA COMPETENCIA MUNICIPAL SOBRE EL SERVICIO: 1. La afirmación de la competencia no se pronuncia sobre la correlación entre público y privado en la gestión del servicio. 2. Las potestades que se derivan de la competencia para la implantación y prestación de servicios públicos. 3. La posición e iniciativa de las empresas privadas en servicios de la competencia municipal. 4. Las vías de iniciativa y ordenación en servicios de competencia municipal. V. LA TITULARIDAD SOBRE EL SERVICIO Y EL MODO DE ACCESO A ELLA. VI. EL PROCEDIMIENTO PARA LA INICIATIVA DE ACTIVIDADES ECONÓMICAS EN CONCURRENCIA: 1. Procedimiento de iniciativa en concurrencia con empresas privadas. 2. Procedimiento para acceder a la titularidad sobre el servicio y su gestión directa en régimen de monopolio. VII. LA OPCIÓN POR EL MODO DE GESTIÓN DEL SERVICIO. DE LA DISCRECIONALIDAD A LOS CONCEPTOS JURÍDICOS INDETERMINADOS: 1. El marco tradicional de la opción de la entidad local por los modos de gestión. Discrecionalidad y vinculación negativa. 2. La reforma operada por la LRSAL.3. Las exigencias de carácter general. Eficiencia y sostenibilidad con un mandato de optimización. La implícita pero inequívoca preferencia de la LRBRL por la gestión indirecta de servicios. 4. Las preferencias legales sobre las concretas modalidades de gestión. VIII. A MODO DE CONCLUSIÓN.

\section{EL MOVIMIENTO REMUNICIPALIZADOR. SUS PLANTEAMIENTOS Y SUS DIVERSOS ENTORNOS}

En tiempos muy recientes, no más allá de dos años, la llamada remunicipalización se presenta en ciertos círculos como el principal objetivo de los entes locales sobre la gestión de sus servicios. Con este novedoso término, escasamente preciso en su caracterización jurídica y definición semántica, se pretende describir un ciclo en la gestión de los servicios locales: unos servicios que, por lo general, se habrían entregado a empresas privadas para su gestión durante las dos últimas décadas del pasado siglo y que ahora se pretenden 
atribuir a los propios entes locales para su gestión directa excluyendo así toda intervención por el sector privado.

Este es en lo esencial el programa del que bien podría llamarse movimiento remunicipalizador impulsado por una serie de estudios, experiencias y fuerzas políticas. Unos estudios que postulan como más eficiente y menos costosa la gestión directa por los propios entes locales. Unas experiencias registradas en algunas de las grandes ciudades europeas, en las que servicios gestionados por empresas privadas han pasado a la titularidad pública. Y unos grupos sociales y políticos de identidad diversa que tienen en común su pretensión de que los servicios municipales sean gestionados de manera directa por los propios municipios excluyendo la actuación de empresas privadas en estos sectores. Se trata por lo demás de grupos que no se adscriben netamente a un determinado partido político sino que tienen una cierta, y limitada, proyección transversal en el espacio público.

Sobre este movimiento remunicipalizador y sus principales planteamientos pueden realizarse diversas precisiones. Una de ellas sobre su ámbito territorial que es, fundamentalmente, el europeo: es en él donde se registran las experiencias que se quieren presentar como emblemáticas y es también en él donde se producen los estudios que más resueltamente abogan por la gestión directa de los servicios locales. Y en ese espacio territorial cabe advertir a su vez una clara distinción entre los Estados del norte y centro de Europa, por un lado, y los estados del sur, por otro: las remunicipalizaciones relevantes, aquellas que se presentan como emblemáticas, se han realizado en ciudades del norte y centro de Europa: Londres, París, Berlín, Estocolmo, Budapest. En cambio, en los Estados del sur de Europa no se cuenta ninguna remunicipalización significativa. Así se constata en Italia, España y Portugal. Según los propios estudios realizados desde la perspectiva remunicipalizadora, son muy escasos los municipios espańoles que en los diez últimos ańos han optado por la gestión directa municipal del servicio de abastecimiento de agua, que se toma como referencia en varios de estos análisis².

Así el informe de E. Lobina, S. Kishimoto y O. Petitien (2015), Là pour duser: La remunicipalisation de l'eau, un phénomène global en plein essor. (Transnational InstituteObservatoire des multinationales), ofrece una lista de 180 casos en todo el mundo de remunicipalizaciones del servicio de abastecimiento de agua realizadas en lo que llevamos de siglo. En Europa el mayor número se registra en Alemania y Francia, afectando también a grandes municipios y ciudades. Pero por parte de España solo figuran once municipios, todos de pequeño o, como mucho, medio tamaño: Alfes, Arenys de Munt, Arteixo, Figaró-Montmany, Ermua, Guadalcacín, Estella del Marqués, Huesna, Montornés del Vallés, Torrecera, La Línea de la Concepción. Tampoco en Italia el movimiento remunicipalizador muestra una gran potencia, pues solo se refieren dos casos: Varese y el abastecimiento de la región de Reggio Emilia. 
Con la concentración de las experiencias remunicipalizadoras en el norte y centro de Europa se hace visible otra explicación y precisión sobre el movimiento remunicipalizador que deriva del diferente entorno económico y financiero de los municipios en una y otra zona. En el norte, su situación presupuestaria ha devenido por lo general más estable para los municipios, que encuentran por lo demás buenas condiciones financieras para afrontar los elevados costes que asumir la gestión directa de servicios les comporta. En el sur de Europa la persistencia de la crisis y el déficit municipal hace más gravoso a los municipios acometer la gestión directa de servicios, para lo que se encuentran además con dificultades para obtener buenas condiciones de financiación ${ }^{3}$.

El entorno económico deviene así un elemento que delimita y singulariza muchas situaciones, evitando de esta manera las generalizaciones tanto sobre la conveniencia remunicipalizadora como, en su momento, sobre las opciones de gestión privada, que muy significativamente se produjeron en muchos casos por las dificultades financieras y presupuestarias en las que se encontraban muchos municipios por causas diversas: desde las derivadas de la crisis económica que afectó a Europa, particularmente a los Estados del sur, hasta las que se dieron en Alemania con motivo de la reunificación y que afectaron de manera muy especial a la ciudad de Berlín ${ }^{4}$, pasando por las ne-

3 En este sentido se afirma que «en los países del norte de Europa, por ejemplo en Alemania, los municipios, como las demás autoridades públicas, tienen muchas ventajas, porque pueden conseguir créditos, préstamos o financiación del sistema bancario a una tasa de interés muy baja, casi cercana al cero por ciento. Muchas autoridades locales han aprovechado estas condiciones ventajosas para financiar la remunicipalización de los servicios locales. Por el contrario, en los países del sur de Europa, como en Italia, las autoridades locales no disfrutan de las mismas facilidades financieras», $\mathrm{H}$. Wollmann (2013), «La experiencia de los ordenamientos europeos: ¿un "retorno” a las gestiones públicas municipales?», Cuadernos de Derecho local, 31, pág. 78. Con mayor amplitud y detalle, H. Bauer, C. Büchner y L. Hajasch (2012), Rekomunalisierung öfentlichez Daseinvorge, Postdam: Universität Postdam.

4 Un caso ilustrativo al respecto es el de la remunicipalización del servicio de abastecimiento de agua de la Ciudad-Estado de Berlín, que solicitó un préstamo (a devolver a cargo de las facturas de agua en un periodo de treinta años) para recomprar, en el año 2013, el $49 \%$ de las acciones de la sociedad pública Berlin Wasser Holding AG que, en 1999, había vendido a un consorcio de empresas privadas, alemanas y francesas. Es de destacar también que aquella venta de acciones, que supuso así la privatización parcial de la empresa prestadora, venía fundamentalmente por los agudos problemas financieros que se le plantearon a Berlín con la reunificación alemana en 1993, que afectó de manera muy particular a esta ciudad. 
cesidades de modernizar instalaciones muy desfasadas, como fue el caso de la red de canalización para abastecimiento domiciliario de agua en París.

Otro elemento que deja una marcada impronta sobre las iniciativas remunicipalizadoras es el propio tamaño de los municipios y el consiguiente volumen de los servicios que se les atribuyen. Se constata — de manera aquí sí generalizada- que la gestión directa de sus servicios resulta en buena medida accesible a los pequeños municipios, mientras que en los de mayor tamaño, en las grandes ciudades y conurbaciones, parecen más apropiadas las formas de gestión indirecta. En la docena de municipios españoles que, según los citados estudios, han optado recientemente por las fórmulas de gestión directa son mayoría los pequeños municipios y solo algunos de ellos pueden considerarse de tamaño medio. Muestra ello es que la intensidad del proceso remunicipalizador en Espańa hay sido muy baja, como hemos tenido ocasión de comprobar. Son las remunicipalizaciones que se han operado en algunas grandes ciudades europeas las que han llamado la atención precisamente por eso, por constituir una excepción en el panorama de las grandes ciudades ${ }^{5}$

5 En algún caso la privatización había ido demasiado lejos, hasta dejar servicios básicos en manos de fondos de inversión con una orientación marcadamente especulativa. Es bien significativo el caso del abastecimiento de agua a la ciudad de Londres. En los años ochenta, bajo el Gobierno de Margaret Thatcher, se produjo en Gran Bretaña una privatización a gran escala de los servicios de abastecimiento de agua en los que operaban una decena de empresas públicas. La que operaba en Londres, Thames Water Authority, fue adquirida en 1989 por sociedades gestoras de fondos de pensiones de los Estados Unidos y algunos bancos de la city londinense, cambiando su nombre por el de Thames Water Utilities Limited. En el 2001 esta sociedad fue adquirida a su vez por la empresa alemana RWE, que operaba en el sector de la energía y que con esta adquisición pretendía proyectarse en el sector del abastecimiento de agua, lo que efectivamente hizo en ciudades de todos los continentes. Thames Water Utilities Limited se configuraba así como la cabeza de un poderoso holding, pero sobre ella cayeron también importantes cargas financieras que en buena parte se acababan repercutiendo sobre los usuarios londinenses, que sufrieron importantes subidas en las tarifas sin que se realizaran las necesarias inversiones.

Como correctivo a la privatización de este sector se creó entonces una autoridad reguladora, la Water Services Regulation Authority, que exigió a la compañía importantes inversiones que no afrontó. Ello condujo a su venta en el año 2006 a Kemble Water, un consorcio constituido en torno a Bank Macquaire, un banco de inversiones australiano. En 2011 el 15\% de las acciones fueron vendidas al fondo soberano Abu Dhabi Investment Authority y al año siguiente un porcentaje similar de acciones fue adquirido por el fondo soberano China Investment Corporation. Sobre el tema, S. Halmer y B. Hausenschild (2014), Remunicipalisation of public services in the EU, Viena: Österreichsche Gesellschaft für Politikberatung und Politikentwicklung, 2014, 
y conurbaciones en las que lo ordinario es la gestión por empresas privadas especializadas ${ }^{6}$.

Lo que se desprende de esa diversidad de entornos y situaciones, absolutamente normal por otra parte, es que no puede establecerse una solución única y generalizada, sea en el sentido de la remunicipalización o gestión directa, sea en el sentido de la gestión por empresas privadas. Ahí se explica por lo demás el amplio abanico de fórmulas de gestión que ofrece la legislación de régimen local. Son, en definitiva, toda una serie de variables las que en principio

págs. 16 y ss. También se cita como una experiencia negativa la atribución de la gestión del servicio de transporte público del Metro de Estocolmo a la empres MTR, radicada en Hong Kong, con problemas ańadidos y embarazosos de tipo fiscal, por tratarse de una empresa no europea.

6 Así lo mantiene Anne Le Strat, teniente alcalde del Ayuntamiento de París y presidente de Eau de Paris en la introducción del informe L'eau à Paris. Retour vers le public, Paris: Eau de Paris, 2014. El caso de París, que supone una excepción a esta regla, ha sido por ello muy comentado. En 1984, siendo alcalde de la ciudad Jacques Chirac, se atribuyó mediante concesión a dos empresas la distribución del agua en París: la Compagnie des Eaux de Paris se encargaba de la zona situada en la orilla derecha del Sena y la compañía Parisienne des Eaux, de la orilla izquierda. Otra empresa se encargaba de la producción y captación en alta del recurso. Esta empresa se configuró por entonces como una sociedad de economía mixta, Société anonyme de gestión des Eaux de Paris, y se dio entrada en su capital a las dos compañías distribuidoras privadas, un $14 \%$ cada una, y el resto de capital del municipio de París. A esta empresa mixta también se le otorgó un contrato de concesión por veinticinco ańos. Toda esta operación, que daba entrada al capital privado, pretendía afrontar un problema económico o financiero peculiar, como lo era en Berlín (tal como acabamos de comprobar, nota 3) el derivado de la reunificación alemana. En el caso de París ese problema era la fuerte inversión que requería la renovación de su muy antigua red de distribución y canalizaciones por la que se producían grandes pérdidas de agua y amenazaba con quebrarse en muchos tramos. Se produjo una tensión entre la Villa de París y las empresas privadas en torno a las inversiones a realizar. Las empresas renovaron la red y redujeron al mínimo las pérdidas, pero las tarifas del agua se elevaron muy considerablemente. El caso es que al expirar los contratos en el año 2010 (no se produjo por tanto ningún rescate o extinción anticipada), París decidió acometer la gestión directa de todo el servicio que encomendó a un établissement public en régimen de regie: Eau de Paris. Ante un recurso presentado por algunos concejales del Consejo de París (con las empresas privadas se alcanzó un acuerdo), una sentencia del Tribunal Administratif de Paris (Jugement du 7 mai 2010) confirmó que este modo de gestión directa estaba entre las opciones de las collectinités locales para organizar sus servicios. Sin embargo, dada la complejidad del servicio, Eau de Paris se ha visto en la necesidad de contratar con empresas privadas asistencia técnica en amplios espacios de gestión del servicio y prestación de Know how. 
habrían de determinar la opción gestora más adecuada: volumen del servicio, complejidad técnica, fórmulas de financiación, impacto presupuestario, etc. Si la opción remunicipalizadora resulta ser la más adecuada, bienvenida sea. No se mantiene aquí ninguna posición a priori al respecto. Todo depende en cada caso de la valoración de unas variables de contenido económico y técnico que no procede tratar aquí, pues este trabajo se centra en el estudio de las vías procedimentales para canalizar la iniciativa municipal en la gestión de servicios públicos, prestando especial atención al procedimiento o procedimientos que puedan conducir a los municipios a la gestión directa de sus servicios con exclusión de la gestión privada.

\section{LAS INEXCUSABLES EXIGENCIAS PROCEDIMENTALES EN LAS INICIATIVAS REMUNICIPALIZADORAS}

Las posibles iniciativas municipales vienen determinadas y dimensionadas en función del procedimiento a seguir en cada caso. Con todo acierto destacó Albi en su momento que ante las dificultades para encontrar en el complejo término de municipalización las «notas esenciales que permitiesen su exacta caracterización, no queda otro distintivo para identificarlo que el procedimiento que le es propio, por lo cual pudiera quizá decirse que se entiende por municipalización un trámite peculiar indispensable para el establecimiento de determinadas formas de gestión municipal» ${ }^{7}$.

El procedimiento tiene además una función legitimadora ${ }^{8}$ que necesariamente debe concurrir cuando se trata de dar cobertura a la iniciativa municipal y más aún si pretende excluir la intervención privada en un servicio o sector determinado.

A todo ello se añaden las novedades todavía recientes de la legislación local ${ }^{9}$ que inciden de manera muy significativa tanto sobre los procedimientos que canalizan la iniciativa municipal en la actividad económica como en los criterios para determinar los modos de gestión de los servicios públicos locales.

7 F. Albi (1960), Tratado de los modos de gestión de las corporaciones locales, Madrid: Aguilar, pág. 242.

8 En el sentido legitimador del procedimiento que desarrollara N. Luhmann (1989), Legitimation durch Verfahren, 2 ed., Frankfurt am Main: Suhrkamp.

9 Particularmente con la reforma operada por la Ley 27/2013, de 27 de diciembre, de Racionalización y Sostenibilidad de la Administración Local, en adelante LRSAL. 


\section{POSICIONES QUE PUEDE OSTENTAR EL MUNICIPIO SOBRE SUS SERVICIOS: COMPETENCIA Y TITULARIDAD}

Los municipios pueden ocupar, fundamentalmente, dos posiciones sobre sus servicios. Una es la posición que asumen por disponer de la competencia que les viene atribuida sobre diversos servicios y otra la posición que pueden alcanzar para ostentar la titularidad sobre servicios públicos locales. Las diferencias entre competencia y titularidad son netas sobre todo en el diverso modo de acceso a estas posiciones y en el distinto alcance de las decisiones que desde ellas puedan adoptarse.

La competencia es el resultado de una atribución directa por el legislador, con carácter general para todos los municipios; es, por tanto, una atribución desde una instancia externa a la voluntad municipal. En cambio, la titularidad sobre un servicio depende del todo de la voluntad de cada municipio para emprender el procedimiento que, si se culmina, conduce a ella.

Desde la competencia puede regularse el servicio pero no hasta el punto de establecer un régimen de gestión pública que excluya la actividad privada tal como pretende el movimiento remunicipalizador. Esa decisión solo es posible adoptarla desde la plataforma que ofrece la titularidad sobre el servicio. Analicemos con mayor detalle estos extremos.

\section{LA COMPETENCIA MUNICIPAL SOBRE EL SERVICIO}

La competencia sobre un servicio la ostenta, pues, la entidad local por atribución directa de la ley. No cabe una autoatribución competencial por parte del municipio u otra entidad local. Ni tampoco se alcanza la competencia a través de un procedimiento o un expediente administrativo.

\section{LA AFIRMACIÓN DE LA COMPETENCIA NO SE PRONUNCIA SOBRE LA CORRELACIÓN ENTRE PÚBLICO Y PRIVADO EN LA GESTIÓN DEL SERVICIO}

La competencia exclusiva que la ley atribuye a los municipios u otros entes locales se afirma fundamentalmente frente a tres categorías de sujetos: frente a las restantes administraciones públicas, de manera particular frente a las administraciones más poderosas y potencialmente invasoras por su proximidad (históricamente la Administración del Estado, luego la Administración de la comunidad autónoma). Se afirma también ante los vecinos, que pueden exigir al municipio que tome las medidas necesarias para la prestación del servicio bajo su competencia. Y se afirma igualmente la competencia ante el 
propio municipio, al que marca su agenda y prioridades sobre todo en lo que son sus servicios mínimos: tendrá que garantizar su prestación y destinar a ellos, con carácter prioritario, las necesarias partidas presupuestarias.

Pero la atribución de la competencia exclusiva al municipio $\mathrm{u}$ a otra entidad local sobre un servicio no conlleva pronunciamiento alguno sobre la correlación entre sector público y sector privado, entre iniciativa pública e iniciativa empresarial privada para su gestión, entre titularidad pública y libertad de empresa. Esa correlación solo se dibuja con trazos precisos si el municipio adopta alguna iniciativa de intervención en la actividad económica y en función de la intensidad con la que se ejerza. Una iniciativa de baja intensidad, por así llamarla, canalizada a través de un procedimiento sencillo permitiría al municipio la gestión directa del servicio en concurrencia con empresas e iniciativas privadas. Otra iniciativa de alta intensidad, que discurre por una línea procedimental más densa y exigente, le conduciría a la posición de titularidad sobre el servicio, pudiendo establecer entonces un sistema de gestión directa en régimen de monopolio que excluyera por tanto la libre iniciativa empresarial privada.

\section{LAS POTESTADES QUE SE DERIVAN DE LA COMPETENCIA PARA LA IMPLANTACIÓN Y PRESTACIÓN DE SERVICIOS PÚBLICOS}

En cualquier caso, la afirmación de la competencia conlleva la atribución al municipio de las necesarias potestades para la ordenación e implantación del servicio y conseguir que se ofrezca a los vecinos en las condiciones características del régimen de los servicios públicos: continuidad, accesibilidad, tarifas razonables ajustadas a costes, atención a grupos sociales desfavorecidos, etc. Para ello se dispone de diversas y muy relevantes potestades, como la reglamentaria, la de autoorganización, la de planificación, la autorizatoria, la sancionadora, la inspectora, etc. A ellas se añaden las potestades ligadas al uso del dominio público, que resulta en muchos casos imprescindible para el tendido de las instalaciones. La atribución de las necesarias potestades para la constitución, implantación y ordenación de los servicios de la competencia de las entidades locales es un presupuesto constantemente aceptado y reconocido por la legislación que tiene su expresión más conocida en el artículo 30 del Reglamento de Servicios de las Corporaciones Locales (RSCL): «Las Corporaciones locales tendrán plena potestad para constituir, organizar, modificar y suprimir los servicios de su competencia, tanto en el orden personal como en el económico o en cualesquiera otros aspectos».

La jurisprudencia ha perfilado la relación de este artículo 30 del RSCL con el art. 85 de la LBRL, sobre los modos de gestión de servicios locales: 
[...] donde se define a los servicios públicos locales como los que prestan las entidades locales en el ámbito de sus competencias, permite considerar que existe, en el ámbito local, una noción de servicios públicos vinculada a la idea de competencia, al reputarse de tales a cuantos tienden a la consecución de los fines señalados como de la competencia de las entidades locales, concepto que al atender no tanto a la idea de titularidad como a la de competencia, trae consigo el que la calificación de una determinada actividad prestacional como de servicio público local no convierta al correspondiente ente local en titular de dicha actividad, ni excluya una eventual prestación a iniciativa de otras Administraciones públicas o a iniciativa de particulares ${ }^{10}$.

\section{LA POSICIÓN E INICIATIVA DE LAS EMPRESAS PRIVADAS EN SERVICIOS DE LA COMPETENCIA MUNICIPAL}

La actuación de empresas privadas en servicios de la competencia municipal sobre los que el municipio no ha asumido la titularidad puede presentar modalidades muy diversas.

Puede tratarse de empresas que ejercen la libre iniciativa empresarial sujeta a la regulación y al ejercicio de las potestades que derivan de la competencia municipal. Empresas que necesitarán de una autorización municipal para iniciar su actividad, posiblemente de otra autorización —o de una concesión demanial - para el uso de cierta intensidad del dominio público municipal; estarán sujetas a la potestad reglamentaria, inspectora, sancionadora del municipio como Administración competente. Las potestades del municipio pueden ir más allá, hasta ejercer la potestad tarifaria fijando y revisando los precios y tarifas que la empresa o empresas puedan cargar a los usuarios al ser su actividad la prestación de un servicio público de competencia municipal.

10 Sentencia del TSJ de las Islas Canarias 114/2009 de 25 de septiembre sobre la gestión del servicio de abastecimiento de agua. Una sentencia que parece inspirarse en una importante Sentencia del Tribunal Supremo que afirma «que existe una noción de servicio público vinculada a la idea de competencia en sintonía con lo reiterado en el artículo 85 LBRL que considera servicios públicos a cuantos tiendan a la consecución de los fines señalados como de la competencia de las entidades locales. Este concepto (servicio público) atiende (en el ámbito local) no tanto a la idea de titularidad como a la de competencia, de manera que la calificación de una determinada actividad prestacional como de servicio público local no convierte al correspondiente ente local en titular de dicha actividad» (STS de 23 de mayo de 1997, Ar. 4065). Para convertirse en titular, podríamos añadir, el ente local habría de ejercitar una iniciativa a través de un procedimiento establecido —el del artículo 97 en sus apartados 1 y 2 del TRRRL - que le situarían, caso de prosperar, en la posición de titular del servicio que queda así publicitado. 
Es posible que toda la intervención municipal sobre una empresa se acabe concentrando y sistematizando de algún modo en un convenio o relación contractual con ella. Se trata de convenios o contratos atípicos que fueron frecuentes en las primeras fases de la prestación de estos servicios pero que se dan todavía en la actualidad ${ }^{11}$.

$Y$ es también posible que el municipio establezca una relación contractual con una empresa privada que materialmente pueda caracterizarse como una concesión de servicio público.

Estas y otras situaciones —alguna puede resultar sorprendente desde la dogmática más estricta- no solo encuentran su cobertura en un análisis abstracto sobre los espacios de actuación que permite la mera afirmación de la competencia municipal sobre los servicios, sino que se ven plenamente confirmadas por la experiencia. Se ha constatado así que:

[...] en efecto, servicios públicos de competencia local como el suministro de agua potable, servicios de limpieza viaria, de recogida y tratamiento de residuos... (art. 251.1 de la Ley Reguladora de las Bases de Régimen Local, en adelante LRBRL) en muchos municipios comenzaron a prestarse por particulares, bien en un área geográfica determinada, bien en todo el término municipal, de manera que lo que comienza de forma transitoria, acaba consolidándose en el tiempo ${ }^{12}$.

Se mantiene así en muchos casos una situación materialmente similar a la de la concesión, pero sin los requerimientos formales de esta modalidad de gestión.

Disponemos ya de estudios solventes ${ }^{13}$ realizados con una cuidada y atenta perspectiva histórica sobre la gestión de los servicios públicos locales que muestran bien a las claras que muchos servicios se han venido gestionan-

11 También es perfectamente posible, y admisible, que esa relación entre la empresa gestora - cuya presencia y operatividad se remonta en muchos casos a los inicios de la prestación del servicio- - y el municipio se articule en torno a fórmulas no contractuales, como pueda ser la participación del municipio en el capital de la empresa privada.

12 F. J. Bauzá Martorell (2014), Naturaleza jurídica de la concesión de hecho consentida por la Administración, Granada: Comares, las cursivas son mías.

13 Entre otros, los de N. Magaldi Mendaña (2012), Los orígenes de la municipalización de servicios en España, Madrid: INAP, y J. M. Matés Barco (1998), Cambio institucional y servicios municipales. Una historia del servicio público de abastecimiento de agua, Granada: Comares. Aunque no es desde luego reciente, proporciona también clarificadora y abundante información la monografía de A. Membiela Guitián (1950), La municipalización de servicios públicos. Especialmente referida al abastecimiento de agua a poblaciones, Madrid: Instituto de Estudios de Administración Local (IEAL). 
do por empresas privadas en régimen de concesión, en muchos casos de hecho y sin un especial envoltorio formal, ostentando el municipio la competencia sobre el servicio sin haber ganado, mediante la oportuna iniciativa y tramitación procedimental, la titularidad sobre el mismo.

En algún momento pudo pensarse que la concesión solo resulta admisible si previamente se afirma la plena titularidad del municipio sobre el servicio. No podría hasta entonces conceder el municipio lo que no es suyo. Sin embargo, esta idea que vincula la concesión a la previa titularidad — que pudo ser útil en el intento de diferenciar netamente la concesión respecto a la figura de la autorización - no se ha visto confirmada por los análisis más rigurosos y tampoco por la experiencia histórica de la gestión de los servicios locales de la que tenemos ya un conocimiento muy significativo.

Por lo demás, la LRBRL avala plenamente esta opción al establecer que «los servicios públicos de competencia local habrán de gestionarse de la forma más sostenible y eficiente de entre las enumeradas a continuación» ${ }^{14}$, ofreciendo el elenco de las formas directas — que requerirán la tramitación de un procedimiento para habilitar la iniciativa municipal - y las formas de gestión indirecta entre las que figura la concesión.

Entre los análisis doctrinales destaca el realizado por F. J. Fernández González ${ }^{15}$, que, tras una delimitación conceptual precisa, concluye de manera muy convincente que el municipio desde la competencia que ostenta sobre el servicio, sin acceder por tanto a la titularidad sobre el mismo, puede otorgar una concesión a una empresa privada. Concesión que no comporta el monopolio sobre el servicio (que se produciría solo en el caso de que el municipio acceda a la titularidad), pues sigue abierto a la iniciativa privada: otras empresas podrían operar en el sector sin necesidad de una concesión.

La única objeción que podría hacerse a esta tesis es que su autor no la somete a revisión en la legislación de contratación administrativa en la que se encuentran fórmulas y pronunciamientos que parecen exigir la titularidad sobre el servicio como presupuesto ineludible para el contrato de gestión de servicios públicos. No hay más que pensar en la figura del rescate del servicio

14 Artículo 85.2 de la LBRL.

15 F. J. Fernández González (1995), La intervención del municipio en la actividad económica. Los títulos que la legitiman, Madrid: Civitas, en especial págs. 319 y ss. Esta percepción era ya muy clara, entre otros, en J. A. López Pellicer (1976), «La concesión de servicios locales", en La concesión administrativa en la esfera local. Servicios, obras y dominio público, Madrid: IEAL, págs. 39 y ss. Del mismo autor, (1982), «Servicio público municipal y actividades particulares de interés público», Revista de Estudios de la Vida Local, 178, págs. 83-112. 
que tiende a fundamentarse en la titularidad sobre el servicio desde la que esta facultad se ejercería.

Aunque ciertamente la legislación de régimen local y la de contratación del sector público no están sintonizadas como sería de desear, creo que esta última no impide que los municipios puedan otorgar un contrato de concesión sobre un servicio de su competencia sin necesidad de asumir previamente la titularidad sobre el mismo. Un contrato con este contenido tendría un carácter inequívocamente administrativo por ser su objeto una materia de la competencia de la Administración contratante, criterio este de la competencia, trasunto del giro o tráfico peculiar de la Administración, que marca la distinción entre contratos administrativos y contratos privados de la Administración ${ }^{16}$.

La propia Ley de Contratos del Sector Público es muy clara al adscribir el contrato de gestión de servicios públicos a la competencia y no a la titularidad: «la Administración podrá gestionar indirectamente, mediante contrato, los servicios de su competencia ${ }^{17}$. En el mismo sentido, las potestades que se reconocen a las Administraciones sobre los contratos de gestión de servicios públicos en la legislación de contratos del sector público no se fundamentan y explican necesariamente en la titularidad de la Administración sobre el servicio. Así, la facultad de rescatar el servicio previamente concedido tiene apoyaturas directas en la potestad expropiatoria, la revocación de los actos administrativos o la facultad de terminación anticipada de los contratos administrativos. Eso sí, en el caso de que el municipio ejercitara esta facultad para rescatar el servicio tendría que asumir entonces la gestión directa ${ }^{18}$ de lo previamente concedido, para lo que debería promover el oportuno expediente para promover su iniciativa económica, de gestión directa del servicio público desde la competencia en los términos que se analizan a continuación.

16 Artículo 19.1.b) de la Ley 3/2011, de 14 de noviembre, de Contratos del Sector Público.

17 Artículo 275 de la Ley 3/2011 de la Ley de Contratos del Sector Público.

18 Como mantienen de manera unánime la jurisprudencia y doctrina, el rescate de un servicio concedido a una empresa privada solo es posible si la gestión del servicio rescatado se encomienda a la gestión directa de la Administración, no resulta admisible por tanto el rescate para entregar la gestión del servicio a otra empresa privada en régimen de gestión indirecta. Esta es una exigencia que de manera unánime requiere la jurisprudencia y doctrina y también, por supuesto, la legislación. La jurisprudencia invocaba frecuentemente el artículo 79 de la Ley de Contratos del Estado al establecer que «si la Administración, antes de la conclusión del contrato, estimase conveniente para el interés general el servicio por sí o por medio de un ente público, podrá ordenar su rescate indemnizando al empresario». Así en la STS de 5 de abril de 1999 en un caso de rescate del servicio municipal de recogida de basuras. 


\section{LAS VÍAS DE INICIATIVA Y ORDENACIÓN EN SERVICIOS DE COMPETENCIA MUNICIPAL}

Sobre los servicios de su competencia el municipio puede adquirir un protagonismo gestor. Para ello, para gestionar directamente el servicio, habría de tramitar el procedimiento para la gestión directa en concurrencia con posibles iniciativas privadas. La gestión pública en régimen de monopolio solo sería posible si previamente se afirma la titularidad del servicio a través de un procedimiento más exigente.

Otra posibilidad que se le ofrece al municipio es la de ordenar y sistematizar de manera integrada el ejercicio de las competencias que ostenta como Administración competente sobre el servicio. Así, ordinariamente, con la aprobación conjunta y coordinada de un reglamento del servicio, un plan de prestación y un estudio para la determinación de tarifa. La adopción de estas u otras medidas de manera integrada, en unidad de acto podríamos decir, no supone que el municipio alcance así la titularidad u otra posición sobre el servicio (no aporta nada en tal sentido), pues se trata simplemente de la ordenación con visión de conjunto (lo que resulta desde luego acertado y deseable) ${ }^{19}$ de unas competencias que de otro modo se ejercerían de manera dispersa.

\section{LA TITULARIDAD SOBRE EL SERVICIO Y EL MODO DE ACCESO A ELLA}

El artículo 86 de la LRBRL de 1985, siguiendo muy de cerca lo dispuesto por el artículo 128 de la Constitución, declaró la reserva en favor de las entidades locales de toda una serie de actividades o servicios esenciales. A mi juicio erróneamente, porque el criterio del artículo 128 de la Constitución es que la reserva se opera de manera singular, caso por caso, mediante ley sectorial y no a través de una ley general como es la LBRL que establece la reserva en bloque de toda una serie de servicios. La modificación de la expresión en el anteproyecto de la Constitución, «la ley podrá reservar», para fijar

19 Así lo prevé, por ejemplo, el Reglamento de Obras y Servicios (en adelante ROAS) de Cataluña, de 1995, que en su artículo 159 lleva por rótulo "Expediente para la implantación del servicio» y que prevé la aprobación conjunta o coordinada de tres instrumentos: la elaboración de una memoria justificativa, la aprobación de un proyecto o plan de establecimiento y la aprobación de un reglamento del servicio. No se trata de un procedimiento que transforme la posición del municipio, que sigue siendo la que la competencia ofrece sobre el servicio, sino de la mera ordenación sistemática de instrumentos reguladores fundados en esa competencia que ostenta. 
el vigente enunciado, «mediante ley se podrá reservar», del artículo 128 de la Constitución se ha considerado siempre muy elocuente al respecto. Por lo demás, y como confirmación del erróneo planteamiento del artículo 82.6 de la LRBRL, la línea sectorial, a la que inequívocamente apuntaba el texto constitucional, ha terminado imponiéndose, pues diversas leyes sectoriales con una marcada orientación liberalizadora han excluido de la reserva del artículo 86.2 de la LRBRL a la mayoría de los servicios que contemplaba, por lo que ahora queda como un precepto residual muy mermado en su contenido ${ }^{20}$.

Además, en otra muestra de disfuncionalidad, este precepto generó una duda y controversia de cierto calado, pues pudo pensarse, de manera hasta cierto punto razonable, que sus determinaciones tenían un efecto directo, produciéndose entonces la asunción de la titularidad, ope legis, por parte de todos los municipios sobre todos los servicios contemplados en ese artículo, sin necesidad por tanto de un procedimiento que condujera la iniciativa municipal hasta la titularidad sobre el servicio.

Pero al cabo de un tiempo se estableció muy claramente en la interpretación jurisprudencial y doctrinal y, sobre todo, en los desarrollos legislativos posteriores $^{21}$, que la mera declaración de la reserva por el artículo 86 de la

20 En la actualidad la reserva del artículo 86.2 de la LRBRL se circunscribe a: «abastecimiento domiciliario y depuración de aguas; recogida tratamiento y aprovechamiento de residuos y transporte público de viajeros». Han abandonado la relación de servicios reservados, por aplicación de la legislación sectorial, los siguientes: suministro de gas y calefacción; mataderos, mercados y lonjas centrales. El precepto prevé que el Estado y las comunidades autónomas "podrán establecer, mediante Ley, idéntica reserva para otras actividades y servicios». Los hechos han discurrido en la otra dirección: no solo no ampliando la relación de servicios reservados, sino reduciendo la lista del propio artículo 86.2 de la LBRL.

21 Especialmente claro al respecto, como destacara en su momento la doctrina, resulta el artículo 244 del Texto Refundido de la Ley Municipal y de Régimen Local de Cataluña al afirmar que «cuando la actividad económica tiene por objeto prestar un servicio público esencial reservado por ley a los entes locales, la adopción de la iniciativa se rige por el procedimiento establecido en el artículo 243.2» con unas particularidades adicionales. Por su parte, el artículo 163.3 del ROAS establece que «cuando la ley declare expresamente reservados a los municipios los servicios esenciales y aquellos opten por la prestación en régimen de monopolio se ha de instruir un expediente de acuerdo con el artículo 183 y concordantes», que son preceptos dictados en desarrollo del artículo 97 del Texto TRRL. De ello se desprende inequívocamente que la titularidad no se alcanza con la declaración legal de reserva, sino que a ella debe añadirse la instrucción de un expediente por la entidad local de que se trate. Una posición muy clara, reparando certeramente en los citados preceptos, en Pablo Menéndez García (1996), «Una 
LRBRL no tenía virtualidad suficiente para entender asumida la titularidad sobre el servicio ${ }^{22}$ y poder entonces ejecutar estas actividades en régimen de monopolio, pues para ello se requiere del expediente previsto en el artículo 97 del Texto Refundido de las Disposiciones Legales en materia de Régimen Local (en adelante TRRL) con la aprobación del órgano de Gobierno de la comunidad autónoma.

En realidad, el artículo 86.2 de la LRBRL ofrece a los municipios la cobertura exigida por la Constitución - la declaración de la reserva en una norma con rango de ley- para que puedan, de manera singular y autónoma, hacer efectiva la reserva, asumiendo la titularidad sobre el servicio y excluyendo así la libre iniciativa privada. Se está operando aquí sobre la correlación entre sector público y sector privado hasta el punto de que puede establecerse un monopolio público con exclusión de la libertad de empresa en un determinado servicio o sector de la actividad económica, de ahí las exigencias tanto de la reserva de ley como de un procedimiento más estricto y riguroso a recorrer por el municipio para acceder a la posición de la plena titularidad sobre el servicio.

Se hace aquí patente, por si no se hubiera ya notado, una clara diferencia sobre el modo de acceder a estas dos posiciones que aquí consideramos: la de la competencia y la de la titularidad. A la competencia solo se accede por expresa declaración legal, con la generalidad propia de la ley que atribuye la competencia a todos los entes locales de una determinada categoría, a todos los municipios por ejemplo; a la titularidad, por el contrario, solo se llega a través de la iniciativa singular de cada municipio que ha de discurrir por el procedimiento establecido al efecto ${ }^{23}$.

La posición propia de la titularidad sobre el servicio es la que permite al municipio la gestión directa excluyendo toda intervención de empresas privadas en la línea a la que apuntan los planteamientos remunicipalizadores que sumariamente se han expuesto al inicio de este artículo. La gestión privada

interpretación renovada de la reserva de servicios esenciales en favor de las Entidades Locales», Revista Española de Derecho Administrativo, 89, págs. 183-212.

22 Sería contrario por lo demás a la autonomía local al eliminar cualquier margen de opción a los municipios sobre la monopolización del servicio.

23 La exigencia de este expediente de iniciativa para acceder a una modalidad de gestión directa ha sido categóricamente ratificada por el Tribunal Supremo al afirmar que «la creación de una empresa municipal no puede hacerse, conforme al artículo 86.1 de la LRBRL, sin un expediente previo para acreditar la oportunidad y conveniencia de la medida. Este requisito aparece justificado por el carácter excepcional que, desde el punto de vista de los principios de libre empresa y libertad de mercado (artículo 38 de la Constitución) reviste la intervención pública en la actividad económica (artículo 128 de la Constitución)» (STS de 28 de junio de 2002, Ar. 7636.) 
solo sería posible a través de las fórmulas, de carácter contractual, previstas en la legislación de régimen local, ordinariamente a través de una concesión de servicios públicos. Con estas concesiones, con estas fórmulas de gestión indirecta, pretende acabar el movimiento remunicipalizador estableciendo un régimen de gestión directa, ya sea cuando se extingan las concesiones otorgadas, ya sea sin aguardar a ese momento mediante el rescate, opción esta última que puede ser muy costosa. En cualquier caso, para adoptar estas medidas necesita el municipio ostentar la titularidad sobre el servicio. No basta con la competencia atribuida por el legislador, sino que es necesario tramitar el procedimiento que se analiza a continuación.

\section{EL PROCEDIMIENTO PARA LA INICIATIVA DE ACTIVIDADES ECONÓMICAS EN CONCURRENCIA}

Los componentes y trámites fundamentales del procedimiento están fijados en el artículo 86 de la LRBRL y el artículo 97 del Texto refundido. Se trata de una regulación que ha incorporado las importantes novedades introducidas por la Ley 27/2013, de 27 de diciembre, de Racionalización y sostenibilidad de la Administración Local (en adelante LRSAL).

Esta ley, conviene destacarlo ya, adopta una orientación muy distinta, opuesta podría decirse, a la del movimiento remunicipalizador. Así, en su Preámbulo manifiesta su objetivo de «favorecer la iniciativa privada evitando intervenciones administrativas desproporcionadas», con ese objetivo "se suprimen monopolios municipales que venían heredados del pasado y que recaen sobre sectores económicos pujantes en la actualidad». Este planteamiento dejará su impronta en los procedimientos — haciéndolos más exigentes al incorporar nuevos trámites - que canalizan la iniciativa económica local.

Un primer procedimiento (o un primer tramo procedimental) es para tramitar la iniciativa que conduce a la gestión directa en concurrencia con empresas privadas. Ese procedimiento se complementa con un segundo tramo, integrado por diversos trámites, para acceder a la titularidad que comporta el monopolio con exclusión de la iniciativa económica privada.

\section{PROCEDIMIENTO DE INICIATIVA EN CONCURRENCIA CON EMPRESAS PRIVADAS}

\subsection{Acuerdo inicial y designación de la comisión de estudio}

Acuerdo inicial de la corporación, previa designación de una comisión de estudio compuesta por miembros de la misma, por personal técnico y por 
representantes de los usuarios como establecen diversas legislaciones autonómicas $^{24}$.

\subsection{Elaboración de la memoria. Sus contenidos. Las exigencias introducidas por la LRSAL}

Esa comisión ha de redactar una memoria que según la legislación básica —artículo 97.1 LRBRL — ha de tener necesariamente dos contenidos mínimos.

a) El más importante no se contiene en este artículo 97 del TRRL, sino en un precepto que figura en una ley de mayor relevancia, como es la LBRL, tras la reforma operada por la LRSAL. El artículo 86.3 de esta Ley establece que:

[...] las entidades locales podrán ejercer la iniciativa pública para el desarrollo de actividades económicas, siempre que esté garantizado el cumplimiento del objetivo de estabilidad presupuestaria y de la sostenibilidad financiera del

24 La jurisprudencia se está mostrando muy exigente en estas determinaciones aparentemente menores y organizativas. Así, la Sentencia del TSJ de Cataluña 1059/2007 de 28 de diciembre anula el acuerdo de un procedimiento de municipalización en régimen de monopolio del servicio de abastecimiento de aguas al constatar «que la comisión en cuestión designada por la Alcaldía y convalidada por el Pleno, no incluía ningún representante de los usuarios [...] que existiendo "asociaciones locales afectadas”, en los términos del transcrito artículo 183.a del ROAS, y por demás, siendo problemático y vecinalmente controvertido el suministro de agua, prestado hasta ese momento, precisamente, con protagonismo de las referidas asociaciones, no consta que se les diera la oportunidad, prevista legalmente, de designar sus representantes y de intervenir por ende en los trabajos de la comisión llamada a definir la procedencia y las características del servicio. [...] Constatado lo anterior — concluye el Tribunal- y que se trata de un incumplimiento sustantivo del procedimiento legalmente establecido, para la válida adopción del acuerdo de municipalización en régimen de monopolio de un servicio esencial, con vulneración de previsiones legales taxativas», la sentencia decide anular el acuerdo del Consejo de Gobierno de la Generalidad, que es el acuerdo final del procedimiento de municipalización en régimen de monopolio, y retrotrae el expediente «al momento en que conforme a las previsiones legales debieron de designarse los representantes de los usuarios».

Debe destacarse que la representación de los usuarios en la comisión no viene exigida por la legislación básica (ni por la LBRL, ni por el TRRL), sino por una norma de rango reglamentario como es el ROAS, lo que da idea del rigor jurisprudencial en la exigencia de estas prescripciones. 
ejercicio de sus competencias. En el expediente acreditativo de la conveniencia y oportunidad de la medida habrá de justificarse que la iniciativa no genera riesgo para la sostenibilidad financiera del conjunto de la Hacienda municipal debiendo contener un análisis del mercado, relativo a la oferta y a la demanda existente, a la rentabilidad y a los posibles efectos de la actividad local sobre la concurrencia empresarial.

Conviene destacar la referencia al «riesgo para la sostenibilidad financiera del conjunto de la Hacienda municipal» que proyecta el análisis económico más allá de la entidad o sociedad local a la que se encomienda la gestión del servicio para valorar el impacto que sobre la Administración matriz — normalmente la Administración municipal — tendría la iniciativa económica.

b) La memoria relativa a los aspectos social, jurídico, técnico y financiero de la actividad económica de que se trate, en la que deberá determinarse la forma de gestión, entre las previstas por la ley y los casos en que debe cesar la prestación de la actividad.

\subsection{Proyecto de precios del servicio}

Un proyecto de precios del servicio, para cuya fijación se tendrá en cuenta que es lícita la obtención de beneficios aplicable a las necesidades generales de la entidad local como ingreso de su presupuesto, sin perjuicio de la constitución de fondos de reserva y amortizaciones.

\subsection{Las exigencias adicionales del RSCL y ahora de las legislaciones autonómicas sobre, en su caso, el anteproyecto de obras}

El RSCL y en su misma línea las legislaciones de diferentes comunidades autónomas, exigen un anteproyecto de las obras e instalaciones necesarias para implantación de la actividad cuando las características del servicio lo requie$\operatorname{ran}^{25}$.

25 Sobre este punto se muestra rigurosa la Sentencia del TSJ de Baleares, 23 de septiembre de 2009, al pronunciarse sobre un caso en el que se ejerció la iniciativa para crear una empresa funeraria municipal. La sentencia efectúa un recorrido por la tramitación del expediente del 97.1 LRBRL y constata que «no se redactó ningún Anteproyecto de obras contemplado en el artículo 61 del RSCL tal y como denuncia la parte recurrente. Es cierto que ese artículo configura su existencia como requisito no indispensable, pues sólo será preciso cuando así se requiriese. Pero en el presente caso sí lo es, pues el 
El presupuesto financiero y el plan de puesta en funcionamiento de la actividad económica proyectada, la rentabilidad prevista y el análisis costebeneficio.

\subsection{Exposición pública de la Memoria y formulación de observaciones por particulares y entidades}

Este es un trámite muy relevante y como tal ha sido destacado por la jurisprudencia:

[...] la exposición pública de la Memoria que, después de ser tomada en consideración por la Corporación, tenía que haber adquirido efectividad práctica por un plazo no inferior a treinta días naturales a los fines de que durante el mismo pudieran formular observaciones los particulares y entidades, trámite que fue omitido por la Administración Municipal, con la consiguiente frustración a los ciudadanos particulares y entidades sociales de sus derechos a verificar alegaciones frente a la Memoria y la propuesta que incorporaba, vedándoseles así su participación en el proceso deliberativo y de toma de decisión pública.

La sentencia concluye que todo ello:

[...] viene a determinar la anulabilidad del acto de la Administración objeto del recurso jurisdiccional, al haberse dictado prescindiendo del trámite esencial previsto en el art. 97.1 del TRRL lo que hace incidir a aquel en la causa de anulabilidad del artículo 63. 2 de la Ley 30/92 de Procedimiento Administrativo Común al derivarse una patente indefensión a todos los que pudieran estar interesados en formular observaciones a la Memoria ${ }^{26}$.

\subsection{Aprobación por el Pleno de la Corporación}

Con esta aprobación, que puede ser por mayoría simple, concluye el procedimiento para ejercer la iniciativa de actividades económicas y prestación directa de servicios en concurrencia con particulares.

Reglamento de los servicios funerarios exige que las empresas que presten el servicio cuenten con determinadas instalaciones».

26 Sentencia del TSJ de Islas Canarias 114/2009, de 15 de septiembre. Es una Sentencia que trata un caso relativo al servicio de abastecimiento de agua. 


\section{PROCEDIMIENTO PARA ACCEDER A LA TITULARIDAD SOBRE EL SERVICIO Y SU GESTIÓN DIRECTA EN RÉGIMEN DE MONOPOLIO}

La tramitación de este procedimiento requiere, como ya se ha destacado, cumplimentar los trámites anteriores y la realización adicional de los siguientes:

\subsection{Informe de la autoridad de competencia correspondiente}

Este es, sin duda, un trámite muy relevante que ha sido introducido mediante la reforma operada por la LRSAL en 2013. Como quiera que se dispone ya de informes de autoridades de competencia de diversas comunidades autónomas recaídos en expedientes de municipalización con monopolio del servicio de abastecimiento de agua conviene detenerse en su doctrina y en los criterios que manejan. De manera prácticamente unánime los informes emitidos mantienen los siguientes criterios:

Primero. Se ha de justificar la conveniencia del monopolio. La entidad local ha de justificar las razones por la que opta por el monopolio, pues comporta una restricción radical de la competencia ${ }^{27}$.

Segundo. Ha de justificarse la concreta modalidad de gestión por la que se opta en la memoria para que sea la menos restrictiva para la competencia. Se considera así necesario, tal como mantiene la Autoridad Catalana de la Competencia, «efectuar un análisis razonado de las diversas alternativas existentes para la gestión de este servicio municipal en régimen de monopolio, que hubiera contribuido a la elección de la forma del servicio más adecuada en términos de competencia» ${ }^{28}$.

Tercero. La gestión directa no se considera la más adecuada puesto que provoca un cierre total del mercado, que cancela así la posible competencia entre operadores «por» el mercado al suprimir la competencia que pueda entablarse en procedimientos de selección entre empresas para

27 En todos los informes se invoca al efecto el Informe 126/7/08 de la extinta Comisión Nacional de Competencia (integrada en la actualidad en la Comisión Nacional de los Mercados y la Competencia) de Recomendaciones a las Administraciones Públicas, donde se afirma que «en aquellos casos en que la consecución de los objetivos definidos requiera introducir, directa o indirectamente, algún tipo de restricciones a la competencia, debería ser necesaria para su aprobación la justificación de la necesidad de tales restricciones».

Informe de la Autoridad Catalana de la Competencia de 26 de marzo de 2015, Santa Maria d'Oló. 
acceder a la gestión indirecta. «No habrá — como afirma la Autoridad Catalana de la Competencia- ninguna posibilidad de que otro operador pueda concurrir para conseguir prestar el servicio de abastecimiento domiciliario de agua potable en el Municipio mientras se mantenga el mencionado encargo de gestión directa» ${ }^{29}$.

Cuarto. Se prefiere siempre la gestión indirecta, «y ello es así —argumenta el Consejo de Defensa de la Competencia de Andalucía - porque el nuevo modelo de gestión supone que los candidatos a participar [...] establecerán una suerte de competencia entre ellos para resultar finalmente elegidos, lo que a su vez debería producir un aumento en la eficiencia en la prestación del servicio » ${ }^{30}$.

Quinto. Las justificaciones han de ser precisas y explícitas desde la perspectiva de la competencia, sobre todo en torno a la conveniencia del monopolio y de la modalidad de gestión por la que se opta. En todos los Informes de Autoridades de la Competencia analizados ${ }^{31}$ las justificaciones dadas por la entidad local se consideran insuficientes ${ }^{32}$.

29 Informe de la Autoridad Catalana de la Competencia de 26 de marzo de 2015, Santa Maria d'Oló.

30 Informe del Consejo de Defensa de la Competencia de Andalucía de 20 de enero de 2009. Municipio de Nerja. Se modificaba el modelo de gestión del servicio del ciclo integral del agua, que pasaba de la gestión directa a un modelo de carácter indirecto basado en un mecanismo de colaboración público-privada. La opción preferencial por modos de gestión indirecta es la conclusión también del Informe de la Autoridad Catalana de la Competencia. La opción preferencial por modos de gestión indirecta es la conclusión del Informe de la Autoridad Catalana de la Competencia al que se ha hecho referencia: «la Autoridad Catalana de la Competencia recomienda al Ayuntamiento de Santa María d'Oló que tome en consideración la posibilidad [...] de convocatoria de un procedimiento de licitación pública, de conformidad con la regulación correspondiente a los contratos del sector público, permitiría suscitar la competencia por el mercado así como desvanecer los riesgos jurídicos detectados». Sobre la relación entre competencia y servicio público en el sector del agua, recientemente C. Rojas Calderón (2016), La distibución de las aguas, Santiago de Chile: Thomson Reuters-La Ley.

31 A los ya referidos cabe añadir los del Consejo de Defensa de la Competencia de Andalucía de 23 de diciembre de 2008 (Ayuntamiento de Nerja) y de 21 de enero de 2010 (Ayuntamiento de Vejer de la Frontera).

32 En los Informes emitidos por el Consejo de la Competencia de Andalucía se concluye que la deficiente justificación «constituye una limitación definitiva del expediente administrativo que impide a este Consejo pronunciarse sobre si se justifica con base 


\subsection{Aprobación por el Pleno de la Corporación por mayoría absoluta del número total de miembros}

Se trata del acuerdo de aprobación del expediente, que en la iniciativa para la actividad económica en concurrencia requiere la mayoría simple del Pleno, pero si la iniciativa es para establecer el régimen de monopolio se requiere mayoría absoluta de los miembros que integran el Pleno.

\subsection{Elevación del expediente al órgano competente de la comunidad autónoma que resolverá sobre su aprobación en el plazo de tres meses}

Esa fiscalización del órgano de gobierno de la comunidad autónoma ha de proyectarse sobre un punto muy concreto, como es la posible incidencia del acuerdo municipal sobre los intereses de la comunidad autónoma, sobre su adecuación a la correlación de intereses entre el plano municipal y el autonómico. Pero se trata de unos intereses y una correlación entre ellos que no queda a la libre apreciación del órgano de gobierno de la comunidad autónoma, sino que tales han de tener su expresión en las competencias legalmente atribuidas. Se trata en definitiva de un control de legalidad, valorando si el acuerdo del municipio percute o invade las competencias legalmente atribuidas a la comunidad autónoma ${ }^{33}$.

\section{LA OPCIÓN POR EL MODO DE GESTIÓN DEL SERVICIO. DE LA DISCRECIONALIDAD A LOS CONCEPTOS JURÍDICOS INDETERMINADOS}

\section{EL MARCO TRADICIONAL DE LA OPCIÓN DE LA ENTIDAD LOCAL POR LOS MODOS DE GESTIÓN. DISCRECIONALIDAD Y VINCULACIÓN NEGATIVA}

La facultad de opción de las corporaciones locales entre las diferentes modalidades de gestión de los servicios se ha configurado tradicionalmente

en criterios de eficiencia la necesidad de explotar el servicio público en régimen de monopolio".

33 Así se explica, y así de interpretarse, la redacción del ROAS en su artículo 184.2 : «[...] la decisión del Gobierno ha de versar sobre la conveniencia y oportunidad del monopolio de la prestación de servicios, en relación con los intereses de la Generalitat». Intereses que han de tener su cumplida expresión en las competencias que la ley atribuye a la comunidad autónoma. 
como una facultad discrecional ${ }^{34}$, expresión del principio de libertad que rige sobre la organización de sus servicios. Se trata de una facultad decisoria que tiende a situarse en la órbita de las potestades de autoorganización. Entre nosotros, el precepto que frecuentemente se invoca al respecto es el artículo 30 del viejo Reglamento de Servicios de las Corporaciones Locales (RSCL), según el cual «las Corporaciones locales tendrán plena potestad para constituir, organizar, modificar y suprimir los servicios de su competencia».

A esta facultad de decidir sobre las fórmulas de gestión se le ha venido reconociendo así una amplia discrecionalidad. Las opciones gestoras quedaban a la libre apreciación de la entidad local, que podría manejar los criterios que estimara convenientes sin necesidad de fundamentar o acreditar de manera precisa las razones que la llevaban a decantarse por una u otra modalidad gestora. Ni tan siquiera se exigía la motivación de esta decisión. No la prescribe la legislación de régimen local, ni tampoco la legislación de procedimiento administrativo.

Este amplio margen de discrecionalidad solo conocía unos límites enunciados negativamente como prohibiciones explícitas, muy escasas por lo demás. En realidad, la única que se establece con carácter básico y general —a reserva de lo que pueda disponer la legislación sectorial respecto a servicios concretos- es la que se contiene en el artículo 95.1, en cuya virtud «los servicios que impliquen ejercicio de autoridad sólo podrán ser ejercidos por gestión directa». El apartado 2 de este mismo artículo contenía una prescripción sobre el arrendamiento de servicios, pero este apartado había sido derogado ${ }^{35}$.

Se conformaba así un régimen que podríamos llamar de vinculación negativa: las corporaciones locales podían optar libremente por cualquier modo de gestión de sus servicios, menos los que estuvieran expresamente prohibidos por la legislación.

Discrecionalidad y vinculación negativa se presentan así como las notas que dibujaban el escenario en el que los entes locales decidían sobre el modo

34 Las limitaciones y rigores no se planteaban por la legislación en la fase de opción por uno u otro medio de gestión, sino en las exigencias requeridas para ejercer la iniciativa —la municipalización en sus diversas variantes_ que sitúe a los entes locales en la posición que les permita optar por determinadas formas de gestión, sobre todo la directa. Pues bien, la reforma operada por la LRSAL ha extremado los rigores en la primera fase, la de la iniciativa, y ha introducido por vez primera limitaciones sustanciales en la segunda, la de la opción por uno u otro modo de gestión. La legislación sectorial puede imponer otras limitaciones u obligaciones sobre concretos modos de gestión. Así, en Alemania hay fuertes restricciones para la gestión mediante formas societarias; en Francia se fija en algunos casos un modo de gestión específico para determinados servicios, como la regie para el de extinción de incendios. Véase al respecto F. Sosa Wagner (2006), La gestión de los servicios sociales, 5a ed., Madrid: Civitas. 
de gestión de sus servicios. Pues bien, ese escenario ha cambiado por completo con el régimen que introduce la LRSAL. Las dos notas que lo caracterizaban se han transformado radicalmente: la discrecionalidad prácticamente desaparece al ser desplazada por una regulación dominada por los conceptos jurídicos indeterminados y la vinculación negativa cede paso a su contrario, un sistema claro de vinculación positiva.

\section{LA REFORMA OPERADA POR LA LRSAL}

La LRSAL introduce exigencias — cuyos contenidos se articulan en una determinada tramitación procedimental- muy relevantes, hasta el punto que alteran la naturaleza discrecional de la decisión por los entes locales sobre los modos de gestión de sus servicios y replantea, rebasándolo, el carácter interno, organizativo, de determinadas decisiones. El artículo 85.2 de la LRBRL queda redactado así:

1. Son servicios públicos locales los que presten las entidades locales en el ámbito de sus competencias.

2. Los servicios públicos de competencia local habrán de gestionarse de la forma más sostenible y eficiente de entre las enumeradas a continuación:

A) Gestión directa: a) Gestión por la propia Entidad Local. b) Organismo autónomo local. c) Entidad pública empresarial local. d) Sociedad mercantil local, cuyo capital social sea de titularidad pública.

Los modos de gestión que la legislación ofrece para la gestión directa de servicios son los mismos que figuraban en la legislación anterior, pero la discrecionalidad para decidir entre ellos se reduce considerablemente al establecer la nueva ley unas exigencias procedimentales que imponen determinadas valoraciones:

Sólo podrá hacerse uso de las formas previstas en las letras c) y d) cuando quede acreditado mediante memoria justificativa elaborada al efecto que resultan más sostenibles y eficientes que las formas dispuestas en las letras a) y b), para lo que se deberán tener en cuenta los criterios de rentabilidad económica y recuperación de la inversión. Además, deberá constar en el expediente la memoria justificativa del asesoramiento recibido que se elevará al Pleno para su aprobación en donde se incluirán los informes sobre el coste del servicio, así como el apoyo técnico recibido, que deberán ser publicitados. A estos efectos, se recabará informe del interventor local quien valorará la sostenibilidad financiera de las propuestas planteadas, de conformidad con lo previsto en el artículo 4 de la Ley Orgánica 2/2012, de 27 de abril, de Estabilidad Presupuestaria y Sostenibilidad Financiera. 
Luego la LRBRL contempla la otra gran opción, por la que manifestará sus preferencias, para la gestión de servicios públicos:

B) Gestión indirecta, mediante las distintas formas previstas para el contrato de gestión de servicios públicos en el texto refundido de la Ley de Contratos del Sector Público.

Esta nueva regulación reduce el margen de discrecionalidad de los entes locales en su decisión sobre el modo de gestión en el caso de que se plantearan fórmulas de gestión directa. En rigor, no se trata de una reducción del margen de discrecionalidad, sino de un cambio de órbita de la decisión sobre el modo de gestión, pues de la órbita de la discrecionalidad pasa a la de los conceptos jurídicos indeterminados. Las determinaciones legales que presiden y condicionan la decisión sobre los modos de gestión de los servicios públicos pueden ser generales, al afectar a cualquier modalidad de gestión, o singulares, específicas de determinados modos de gestión.

\section{LAS EXIGENCIAS DE CARÁCTER GENERAL. EFICIENCIA Y SOSTENIBILIDAD CON UN MANDATO DE OPTIMIZACIÓN. LA IMPLÍCITA PERO INEQUÍVOCA PREFERENCIA DE LA LRBRL POR LA GESTIÓN INDIRECTA DE SERVICIOS}

El modo de gestión que se adopte ha de ser el más sostenible y eficiente de entre los que ofrece la legislación. Esto es algo que se afirma respecto a la primera disyuntiva que se les presenta a los entes locales: la que se abre ante la opción entre la gestión directa y la gestión indirecta. En esta encrucijada, las exigencias de sostenibilidad y eficacia parecen decantar la decisión por la gestión indirecta. Se afirma así en uno de los primeros estudios sobre la incidencia de la LRSAL en esta materia que:

[...] en la disyuntiva de optar por la gestión directa de los servicios o por una de las modalidades contractuales que caracterizan la indirecta, invariablemente se esgrimen los argumentos del menor coste de éstas, la conveniencia de introducir técnicas de gestión privada y adecuadas al mercado y la necesidad de no comprometer un volumen excesivo de recursos públicos. En una coyuntura de crisis económica como la de 2013, las propuestas a favor de la gestión indirecta cobran más fuerza todavía ${ }^{36}$.

36 J. L. Martínez Alonso (2014), «El sector público local: redimensionamiento y gestión de actividades y servicios públicos», en J. A. Carrillo Donaire y P. Navarro Rodríguez (coords.), La reforma del régimen jurídico de la Administración Local, Madrid: La LeyEl Consultor de los Ayuntamientos. 
Una preferencia que es muy clara para la Comisión Nacional de la Competencia, que en su Informe ${ }^{37}$ sobre el anteproyecto de Ley de la LRSAL donde afirmaba que el texto:

[...] debería establecer que las entidades locales opten por fórmulas de gestión indirecta que permitan la prestación privada. Al mismo tiempo, debe asegurarse la revisión periódica del prestador tras el plazo contractual mínimo necesario para asegurar la viabilidad económica de dicha gestión. Esta opción resulta preferible para la competencia y la eficiencia frente a la constitución de entidades instrumentales de capital público o mixto.

En cualquier caso, lo que importa destacar es que hay un mandato legal de optimización — la modalidad de gestión más sostenible y eficiente- que transforma la naturaleza jurídica del marco legal en el que se produce la decisión sobre los modos de gestión; de estar presidido, como antes, por la discrecionalidad pasa a estar dominado por los conceptos jurídicos indeterminados: sostenibilidad y eficiencia.

La consecuencia jurídicamente más destacada del tránsito de la órbita de la discrecionalidad a la de los conceptos jurídicos indeterminados es que en esta, a diferencia de la discrecionalidad, se admite en principio la revisión judicial de la resolución administrativa. La discrecionalidad permite a la Administración optar libremente entre una serie de opciones (cuatro en este caso: las referidas bajo las letras a), b), c) y d) ) y cualquiera que se adopte sería perfectamente válida, ajustada pues a la legalidad que concede este margen de elección, y no susceptible por tanto de revisión judicial. En cambio, en la órbita de los conceptos jurídicos solo existe una sola opción que se ajusta al mandato legal de optimización: la más sostenible y eficiente.

La apertura de este espacio de decisión de las entidades locales a la revisión judicial se hace explícita en el apartado 3 del artículo 86 de la LBRL al puntualizar que «en todo caso, la Administración del Estado podrá impugnar los actos y acuerdos previstos en este artículo [...] cuando incumplan la legislación de estabilidad presupuestaria y sostenibilidad financiera». Aunque este artículo 86 se refiere a la iniciativa económica y no a las opciones por los modos de gestión de los servicios, es evidente que la impugnación de la Administración por entender incumplida la legislación de estabilidad presupuestaria y sostenibilidad financiera puede extenderse a la decisión que la entidad local adopte al decantarse sobre un determinado modo de gestión del servicio si se considera contrario a esta normativa ${ }^{38}$.

37 Informe de 13 de marzo de 2013

38 Por lo demás, la impugnación de estos acuerdos por los motivos aducidos no habría de estar reservada en exclusiva a la Administración del Estado; cualquier persona a la 
Importa mucho, pues, precisar en lo posible el sentido y funcionalidad de estos conceptos de sostenibilidad y eficiencia. Son conceptos que proceden, como explícitamente se reconoce, de la legislación de estabilidad presupuestaria y sostenibilidad que tiene su entronque constitucional en la reforma de la Constitución operada a través de su artículo 135. A su vez, estos conceptos encuentran su sentido en la normativa de las instancias europeas en las que se sitúa en última instancia el impulso y el sentido de esa transcendente reforma constitucional. Así, el artículo 126 del Tratado de Funcionamiento de la Unión Europea, el Pacto de Estabilidad Presupuestaria (cuyas disposiciones se recogen en varios Reglamentos comunitarios), el Protocolo sobre el procedimiento aplicable en caso de déficit excesivo, o el Tratado de Estabilidad, Coordinación y Gobernanza de la Unión Económica y Monetaria.

La Ley Orgánica 2/2012 de Estabilidad Presupuestaria y Sostenibilidad Financiera establece en su artículo 4.2 que «se entenderá por sostenibilidad financiera la capacidad para financiar compromisos de gasto presentes y futuros dentro de los límites de déficit, deuda pública y morosidad de deuda comercial conforme a lo establecido en esta Ley, la normativa sobre morosidad y en la normativa europea».

Con relación a la eficiencia, esta misma Ley afirma en su artículo 9.2 que «la gestión de los recursos públicos estará orientada por la eficacia, la eficiencia, la economía y la calidad, a cuyo fin se aplicarán políticas de racionalización del gasto y de mejora de la gestión del sector público». Se trata de caracterizaciones legales que sin duda pueden ser de utilidad para concretar estos conceptos de sostenibilidad y eficiencia.

En cualquier caso, esta resuelta orientación de la LRBRL hacia la sostenibilidad y eficiencia marca su implícita pero inequívoca predilección por las modalidades de gestión indirecta sobre las de gestión directa por la propia corporación local.

\section{LAS PREFERENCIAS LEGALES SOBRE LAS CONCRETAS MODALIDADES DE GESTIÓN}

Pero la ley va más allá y con relación a los modos de gestión directa fija unos criterios de prelación ${ }^{39}$. La novedad es muy relevante a nuestros efectos,

que los tribunales reconozcan un interés legítimo, que bien podría ser un interés competitivo, habría de considerarse legitimada para impugnar el acuerdo que se decantara por una determinada modalidad de gestión.

39 Como se ha destacado, «su utilización deja de ser, para graduarse en función de la eficiencia y sostenibilidad económica de las opciones existentes», L. Mellado Ruiz 
puesto que si el horizonte del movimiento remunicipalizador es situar los servicios locales en la órbita de la gestión directa, es del mayor interés entonces conocer las preferencias de la legislación entre los distintos modos de gestión directa que ofrece.

Tras la reforma operada por la LRSAL, la LRBRL se muestra renuente respecto a las fórmulas que comportan la creación, como ente gestor, de una persona jurídica sujeta al Derecho privado. Se trata en concreto de las opciones que se recogen en el artículo 85 de la LRBRL apartado 2, letra A) ... c) gestión por Entidad pública empresarial local y d) gestión por Sociedad mercantil local. Opciones por las que solo pueden optar los municipios si media la tramitación de un expediente en el que se requiere la elaboración de dos memorias.

Una es la memoria que justifique que esas fórmulas resultan más sostenibles y eficientes que las fórmulas centralizadas y plenamente sujetas al derecho público que se contemplan en las letras a) gestión indiferenciada y b) gestión por organismo autónomo local. Se fijan, además, los criterios de valoración que ineludiblemente habrán de tenerse en cuenta en esa memoria justificativa: los de rentabilidad económica y recuperación de la inversión ${ }^{40}$.

La otra es la memoria justificativa del asesoramiento recibido. Estas memorias se habrán de elevar al Pleno con informes sobre el coste del servicio y del apoyo técnico recibido.

Todos estos materiales deberán ser — dice la ley literalmente- «publicitados». De ello se deduce que el expediente de constitución de la entidad pública empresarial o de la sociedad mercantil habrá de someterse a trámite de información pública ${ }^{41}$. De hecho esta exigencia de sometimiento a información pública para la constitución de este tipo de entidades en el ámbito local se encontraba ya en algunas leyes autonómicas y era una reivindicación generalizada en la doctrina.

(2016), «Crisis económica y Administración Local: Balance de una incorrecta vinculación", en A. Ezquerra Huerva (dir.), Crisis económica y Derecho Administrativo, Madrid: Thomson Reuters/Aranzadi, pág. 134.

40 Esta memoria viene exigida por la legislación sobre estabilidad presupuestaria cuando afirma que «los actos administrativos, los contratos y los convenios de colaboración, así como cualquier otra actuación de los sujetos incluidos en el ámbito de aplicación de esta Ley que afecten a los gastos o ingresos públicos presentes o futuros, deberán valorar sus repercusiones y efectos, y supeditarse de forma estricta al cumplimiento de los principios de estabilidad presupuestaria y sostenibilidad financiera» (art. 7.3 Ley Orgánica 2/2012, de Estabilidad Presupuestaria y Sostenibilidad Financiera).

41 Así lo entienden los primeros comentarios de esta regulación, como el de J. L. Martínez-Alonso (2014: 601). 
Hay por tanto en la LRBRL, tras la reforma operada por LRSAL, una clara preferencia por las fórmulas a) gestión por la propia entidad local (que ofrece a su vez dos variantes: gestión indiferenciada y gestión desconcentrada por órgano especial) y b) gestión por organismo autónomo local. Se trata de los modos de gestión más vinculados, más dependientes desde el punto de vista organizativo, al municipio. Los menos desconcentrados, por decirlo de otro modo ${ }^{42}$. Son por tanto las estructuras organizativas con menor grado de autonomía en lo relativo a toma de decisiones. Son también las fórmulas con menor flexibilidad en la gestión por cuanto están plenamente sujetas en su actuación, contratación, personal, régimen patrimonial al derecho administrativo, con la sujeción a los controles y procedimientos característicos.

Son, por otro lado, los modos de gestión con mayor rigor y control del gasto público y de ahí la opción preferente por ellos que adopta esta legislación que tiene como objetivo la sostenibilidad financiera y la racionalidad en el gasto público.

Para la caracterización general de los organismos autónomos, las entidades públicas empresarial y las sociedades de capital público, la legislación de régimen local se remite, en lo que resulte de aplicación, a la LOFAGE. Una remisión que debe entenderse ahora realizada a la Ley de Régimen Jurídico del Sector Público (LSP). Pues bien, en esta ley se afirma la general sujeción de los organismos autónomos al derecho administrativo (art. 99 LSP); que su contratación «se ajustará a lo dispuesto en la legislación sobre contratación del sector público» (art. 100. 2 LSP); o la presencia en ellos de personal funcionario (art. 100.1 LSP).

Todos estos rasgos de identidad y régimen jurídico hacen del organismo autónomo local una fórmula organizativa idónea para servicios de carácter administrativo o que impliquen el ejercicio de autoridad, pero nada apropiada para la gestión de servicios de carácter económico, mercantil e industrial que requieren de una estructura de gestión flexible y sujeta al derecho privado en muchos aspectos de su actividad. No parece así la fórmula adecuada, como confirma la realidad de muchos municipios, para la gestión de servicios como el de transporte público de viajeros o el de abastecimiento de agua, sobre todo en grandes ciudades, que figuran entre los objetivos del movimiento remu-

42 La LRSAL adopta así una opción contraria a la que mantenían algunas leyes autonómicas que se decantaban por fórmulas societarias o de derecho privado. Tal era el caso de la Ley Foral 6/1990, de 2 de julio, de Administración Local de Navarra: «Los servicios municipales se prestarán preferentemente a través de Sociedad mercantil, con participación exclusiva o parcial de la Entidad local en el capital social, o de Cooperativa» ( art. 206). 
nicipalizador. Esta posición de la LRBRL con su opción preferente, entre los modos de gestión directa, por los más rígidos y centralizados guarda su coherencia por la previa opción por modos de gestión indirecta en la prestación de servicios.

La conclusión que se desprende es que los servicios de carácter administrativo o que impliquen el ejercicio de autoridad se adscriben a la gestión directa, en las modalidades de gestión indiferenciada, por órgano especial o por organismo autónomo. Para la gestión de servicios económicos con complejidad técnica se mira a las formas de gestión indirecta.

\section{A MODO DE CONCLUSIÓN}

El movimiento remunicipalizador, cuyo programa es el establecimiento o la recuperación de la gestión directa de servicios locales, excluyendo la iniciativa privada, ha tenido sus logros más relevantes en algunas grandes ciudades del centro y norte de Europa. En Espańa y en el área mediterránea las remunicipalizaciones han sido muy escasas, afectando únicamente a pequeños municipios. El diferente entorno económico, sobre todo en punto al déficit municipal y condiciones financieras, configurado por la crisis y sus efectos, explica el distinto alcance de la remunicipalización en una y otra zona de Europa.

La legislación de régimen local, sobre todo tras la reforma operada por la LRSAL, que asume el panorama de crisis y sostenibilidad, tampoco resulta favorable - sin que tampoco la impida en absoluto- a la remunicipalización. Un planteamiento que se hace bien visible en tres momentos decisivos: primero, al incorporar nuevas exigencias, entre ellas el informe de la autoridad de la competencia, al procedimiento para acceder a la titularidad municipal sobre el servicio. Segundo, al manifestar la opción preferente por los modos de gestión indirecta. Tercero, al preferir, entre los modos de gestión directa, aquellos que son idóneos para servicios administrativos o que impliquen el ejercicio de autoridad, pero no para la gestión de servicios de contenido económico, con destacada complejidad técnica y de gestión, sobre todo en grandes municipios y conurbaciones. 